\title{
AN AUTOMATED SYSTEM FOR BODY TEMPERATURE MONITORING OF CHILDREN, PEOPLE WITH DISABILITIES AND BEDRIDDEN PEOPLE USING A CONTINUOUS ANALYSIS
}

\author{
${ }^{1}$ Azambek TURAKULOV, ${ }^{2}$ Fotima MULLAJONOVA \\ ${ }^{1}$ The Namangan Institute of Engineering \& Technology, aturakulov1@ mail.ru \\ ${ }^{2}$ The Namangan Institute of Engineering \& Technology, fmullajonova@ mail.ru
}

\begin{abstract}
The article discusses one of the ways to monitor human health through a continuous comparative analysis of skin temperatures on various parts of the body. Comparing the temperatures of such parts as the armpit, limbs of the arms and legs, it is proposed to draw a conclusion about the state of blood circulation and blood density. A detailed algorithm for processing the measured temperatures is presented. An automated data processing and notification system is proposed. The description of the initial version of the device developed by the authors is given, where the assumptions about possible health problems are notified using light lamps and an audio signal. An inexpensive Arduino NANO microcontroller is proposed as a technical tool for an information processing device.. The research results can be applied in automated systems as hardware and software. The device can be useful in constant monitoring the health status of newborns, people with serious disabilities and people with limited ability to move independently.
\end{abstract}

Keywords: human body temperature, human health monitoring software, automated data processing system.

\section{INTRODUCTION}

The human body temperature is the main indicator of his or her condition. It reflects the results of all biochemical processes in the human body. Even a slight change in body temperature from normal, both upward and downward, as a rule, is a cause for concern.

Body temperature can be maintained by three processes: metabolism, mechanically (for example, muscle tremors from the cold, body massage) and heat exchange with the environment [1].

The last two processes have obvious reasons and can be regulated by external heating or cooling. The first process, according to sources, is regulated by the hypothalamus of the brain. [2]. This process reflects the state of biochemical processes in the human body.

Low body temperature under normal conditions, for example, at room temperature, may be a sign of passive biological processes in the body [3]. For example, when the temperature is very low - up to $35.2^{\circ} \mathrm{C}$ it can be a symptom of diseases such as decreased thyroid function, weakened immunity, the consequence of radiation exposure, and a severe hangover. A moderate drop in temperature - from 35.3 to $35.8^{\circ} \mathrm{C}$ - may indicate chronic fatigue syndrome, depression, malfunctioning of the liver and gall bladder, the first manifestations of diabetes, impaired protein metabolism.

An increase in body temperature is a natural reaction of the human body to such external and internal influences as infection, overheating, stress, insect bites, intense physical activity, various injuries, eating hot food, wearing warm clothes, etc.
By raising the temperature by several degrees during infection, the body fights against pathogens on two fronts.

Firstly, the higher the temperature, the more the body produces interferon, a specific protein that neutralizes viruses.

Secondly, the causative agents of some diseases cease to multiply in heat [4].

Dr. Robert S. Mendelssohn argued that colds, flu, and any other infection would not raise a child's body temperature above 41 degrees, and temperatures below this level would not cause longterm harm. Therefore, it is not necessary to bring down body temperature [5].

Specialists in infectious diseases, as well as mathematics and statistics from McMaster University in Hamilton (Ontario, Canada) on a mathematical model showed that sometimes (for example, with a flu illness) unreasonable lowering of the temperature can even lead to additional deaths [6].

Despite all this, most people when they detect a high temperature first of all try to lower it to a normal level.

People's fear of high body temperature is associated with its irreversible consequences such as pulmonary and cerebral edema, dystrophic changes in the heart muscle, cerebral hemorrhage, damage and death of nerve cells, and respiratory arrest. This condition is most dangerous for young children, the elderly and patients suffering from cardiovascular pathologies and diseases of the central nervous system. But these consequences can 
arise as a result of a rise in temperature to a critical level - closer to $42^{\circ} \mathrm{C}$.

At a paretic body temperature $-39^{\circ} \mathrm{C}-41^{\circ} \mathrm{C}$, the consequences can be problems with the nervous system, dehydration, disturbance of the natural circulatory processes, a sharp jump in blood pressure, an increase in blood viscosity, the onset of a convulsive state, and in small children, febrile fever with loss of consciousness [7].

Many scientific papers have been published on the measurement of human body temperature each year.V.V.Vasilenko in his works studied the history of measuring the temperature of human body according to the works of 57 scientists of the XIVXIX centuries. He distinguished six states according to the temperature value: when body temperature is less than 36.6 - subnormal, from 36.6 to 37.4 - normal, from 37.5 to 38 - subfebrile, over 38 - fever (febrile), above 39.5 - "high" fever, above $42{ }^{\circ} \mathrm{C}$ - hyperpyrexia [8].

Usually people measure body temperature at different parts of the skin: in ear (tympanic), at forehead, under the armpit (axillary), in the mouth, etc. Mainly, mercury, electronic (often called digital), stripe and non-contact infrared thermometers are mainly used to measure human body temperature [9-17].

Using of mercury thermometers has some disadvantages.

Firstly, the case of such thermometers is made of glass or quartz. With little negligence, they can be broken, and mercury can seep out. Evaporation of mercury is known to be very dangerous to human health.

Secondly, the temperature indicator of mercury thermometers is visible only from a certain angle, which makes it difficult for people with poor eyesight to use the thermometer.

Thirdly, mercury and electronic thermometers record only the maximum temperature reached during the measurement. In other words, the indicators of these thermometers only grow, do not fall. On the one hand, it is convenient for viewing the result for a long time after the measurement. On the other hand, the time for measuring temperature with such thermometers is from 3 to 15 minutes, and if the temperature has already begun to fall during this period, it is not determined.

Temperature measurement with non-contact thermometers is not always acceptable, since sometimes the internal body temperature may not be reflected on the surface of a person's skin. The reason for this may be poor blood circulation, exposure to the environment, the property of thermal conductivity of the skin (for example, thick rough skin does not allow the internal temperature of the body to pass out quickly enough) or other factors unknown to us.

The temperature of patients in a hospital setting is measured regularly, and in intensive care units there is the possibility of continuous monitoring.
But at home, the signal for measuring temperature can only be symptoms of illness or complaints from children and the elderly bedridden. Since small children, especially new-borns, are not yet able to inform mothers of their ailments, and mothers cannot always identify symptoms of hypothermia or hyperthermia, they need constant monitoring of the baby's body temperature.

Currently, many devices have been invented in the world that constantly monitor states of health of children, including body temperature. But most of them are designed to measure temperature at one of the often selected points - orally, rectally, armpit. For example, "ThermoSpot" and "Boardbug Baby and Child Monitor" devices invented by John Zeal [18], a well-known body temperature specialist, measure body temperature at a certain point and transmit the corresponding information in the form of a symbol (emoticon or sound).

This article substantiates the possibility of using the "Dallas 18B20" temperature sensor in measuring the temperature of the human body. An automated system is proposed for continuous monitoring of a person's state by a comparative analysis of temperatures obtained from different parts of the body at the same time.

The proposed system can be used for continuous monitoring of new-borns, elderly people, people with disabilities, as well as people with limited mobility.

In addition, the system can be used by ecotourists, geologists and travellers in places remote from civilization.

In automated systems, the sensor can be controlled by microcontrollers. Figure 1 shows the connection diagram of the sensor to the microcontroller Arduino Nano.

The Dallas 18B20 sensor uses the one-wire interface developed by Dallas Semiconductor Corporation. This protocol allows to connect multiple sensors to one cable with three (in parasite mode of two) wire simultaneously. At the same time, each sensor is identified by a unique serial code with a length of 64 bits. The code is stored in the ROM of each sensor.

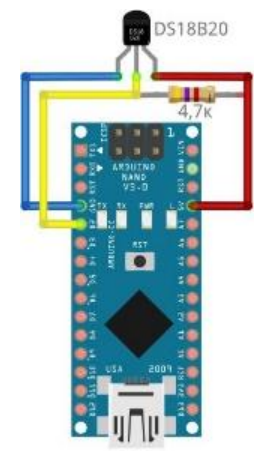

Fig. 1. A connection diagram of the Dallas 18B20 sensor to the Arduino Nano microcontroller. 
This feature of the sensor enables us to measure the temperature in different parts of the human body at the same time.

Figure 2 shows some connection diagrams of multiple sensors to the microcontroller using only one cable.
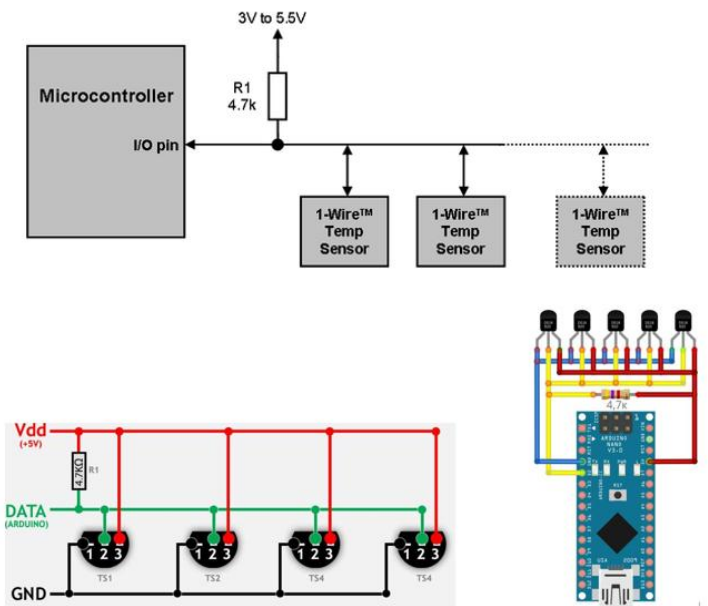

Fig. 2. Connection diagrams of multiple sensors to the microcontroller using one-wire.

\section{JUSTIFICATION OF THE APPLICABILITY OF THE DALLAS 18B20 SENSOR FOR MEASURING HUMAN BODY TEMPERATURE.}

Currently, there are a lot of scientific works devoted to the use of a DS18B20 sensor for measuring human body temperature [19]. But all the experiments were carried out regardless of the time of measurement, which is an important factor for a quick response to temperature change.
In order to study the applicability of the sensor for measuring human body temperature, we (the authors) conducted many measurements on ourselves. For comparative analysis, we chose a conventional mercury thermometer, an electronic thermometer of the brand BEROTHERM 66 (Germany) and the Dallas 18B20 sensor connected to the Arduino Nano microcontroller according to the diagram shown in Fig. 1.

The measurements were carried out in three places of the body: in the ear canal, armpit, and on the tips of the hands, pressing the thermometer sensor between the thumb and forefinger. The ambient temperature was $24^{\circ} \mathrm{C}$.

The readings of the Dallas 18B20 thermometer were observed on a computer screen connected to the Arduino Nano microcontroller via a USB port. The thermometer reached the temperature of the other two thermometers $-35.5{ }^{\circ} \mathrm{C}$ in 20 seconds. After another 20 seconds, it showed $35.75{ }^{\circ} \mathrm{C}$ and did not rise anymore. Measuring was stopped after 100 seconds. As other high precision non-contact medical thermometers showed, it was the real temperature of the fingertips.

The mercury thermometer scale starts at $35^{\circ} \mathrm{C}$. The mercury level reached this value in 40 seconds after starting of the measurement. Over the next 30 seconds, the indicator of the thermometer reached $35.3{ }^{\circ} \mathrm{C}$ and did not rise within 100 seconds.

The BEROTHERM 66 thermometer began to read from $32.9{ }^{\circ} \mathrm{C} 10$ seconds after starting of the measurement. Within 90 seconds, the indicator reached $35.5^{\circ} \mathrm{C}$ and no longer rose up within 100 seconds.

Figure 3 shows the measurement graphs of three thermometers for visual comparison of the results.

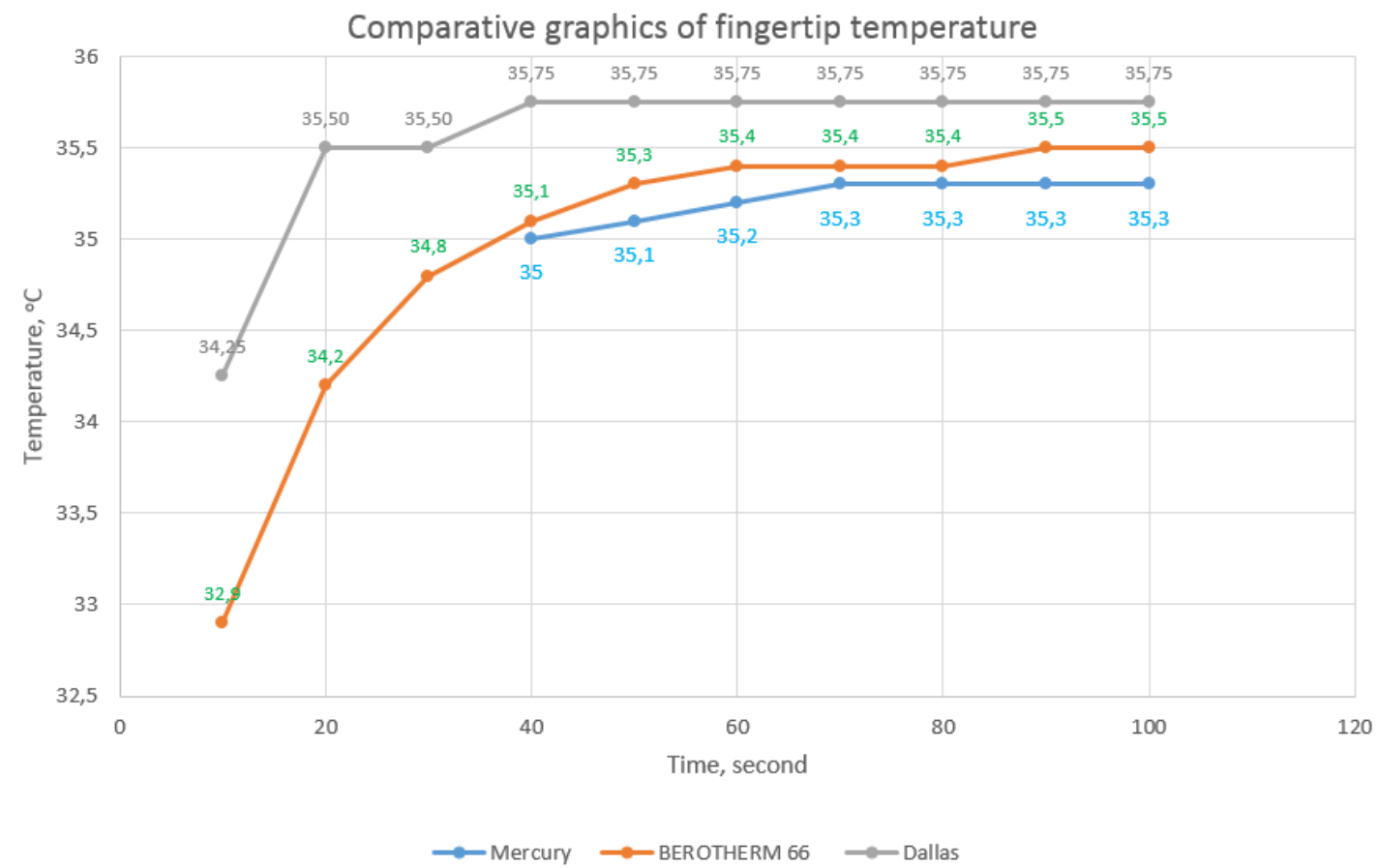

Fig. 3. Fingertips temperature measurement graphs with use of three thermometers. 
As presented in the picture, the Dallas 18B20 thermometer in the shortest time (in 40 seconds) showed the real body temperature.

It should be noted that the indicators of the other two thermometers also reached the mark of 35.7 for a rather long time: mercury in 10 minutes, digital in 7 minutes.
In the same way, we measured the temperature of the armpit and ear canal. The measurement results of the armpit temperature are shown in Figure 4.

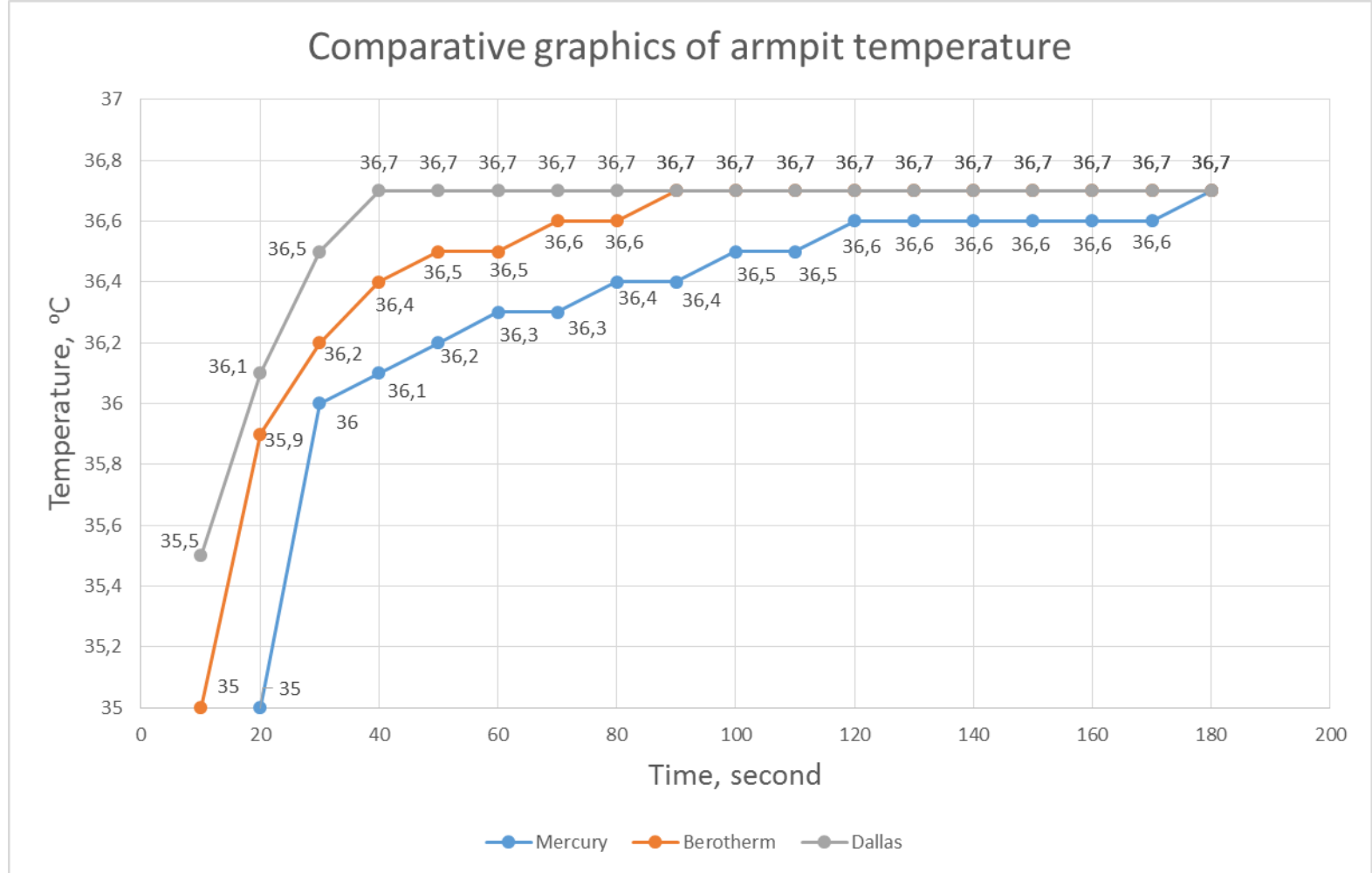

Fig. 4. Armpit temperature measurement graphs with use of three thermometers.

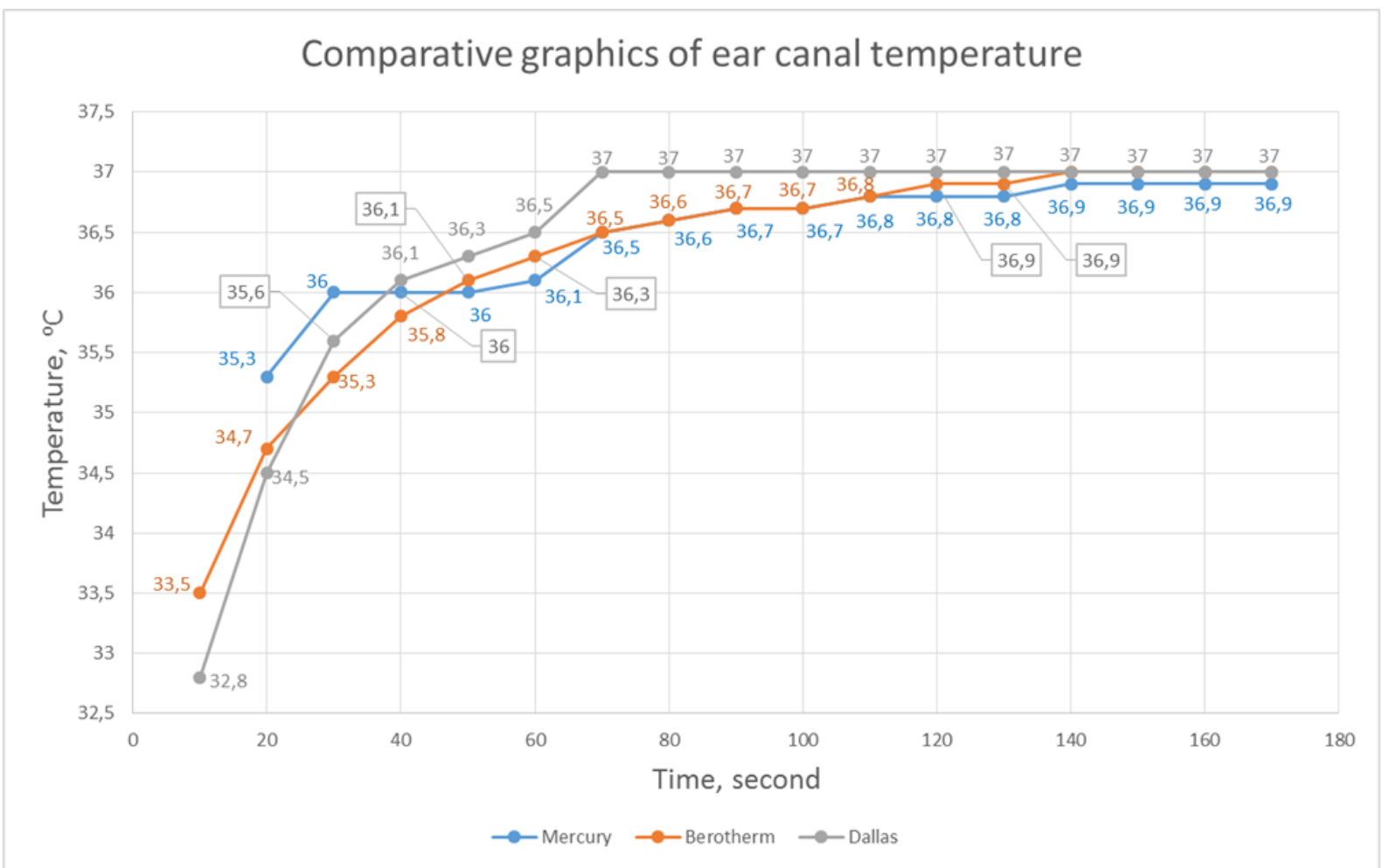

Fig. 5. Ear canal temperature measurement graphs with use of three thermometers. 
It is visible on this graph that the Dallas 18B20 thermometer showed the actual body temperature in the shortest time among the three thermometers.

The measurement results of the ear canal temperature are shown in Figure 5.

This graph shows that at the beginning (up to 40 seconds), the Dallas 18B20 thermometer showed a slow result (it warmed up more slowly than the other thermometers) but within 70 seconds it reached a real temperature of $37{ }^{\circ} \mathrm{C}$, when as a mercury thermometer showed it in 140 seconds, and an electronic one in 180 seconds.

It should be noted that the experiments were carried out many times, and all of them showed identical results. 225 temperature measurements were done on 25 healthy volunteers ( 17 of them are members of autors' families). The summary results are shown in Table 1.

Tab.1. The number of measurements that took the appropriate time to reach the desired temperature

\begin{tabular}{|c|c|c|c|c|c|c|c|c|c|}
\hline \multirow{2}{*}{$\begin{array}{l}\text { Thermo- } \\
\text { meter }\end{array}$} & \multicolumn{3}{|c|}{ Mercury } & \multicolumn{3}{|c|}{ BEROTHERM 66} & \multicolumn{3}{|c|}{ Dallas D18B20 } \\
\hline & $\begin{array}{c}\text { Fingertip } \\
\left(35^{\circ} \mathrm{C}\right)\end{array}$ & $\begin{array}{c}\text { Armpit } \\
\left(36.6^{\circ} \mathrm{C}\right)\end{array}$ & $\begin{array}{c}\text { Ear } \\
\text { canal } \\
\left(36.9^{\circ} \mathrm{C}\right) \\
\end{array}$ & $\begin{array}{c}\text { Fingertip } \\
\left(35^{\circ} \mathrm{C}\right)\end{array}$ & $\begin{array}{l}\text { Armpit } \\
\left(36.6^{\circ} \mathrm{C}\right)\end{array}$ & $\begin{array}{c}\text { Ear } \\
\text { canal } \\
\left(36.9^{\circ} \mathrm{C}\right)\end{array}$ & $\begin{array}{c}\text { Fingertip } \\
\left(35^{\circ} \mathrm{C}\right)\end{array}$ & $\begin{array}{c}\text { Armpit } \\
\left(36.6^{\circ} \mathrm{C}\right)\end{array}$ & $\begin{array}{c}\text { Ear } \\
\text { canal } \\
\left(36.9^{\circ} \mathrm{C}\right)\end{array}$ \\
\hline 10 & 0 & 0 & 0 & 0 & 0 & 0 & 0 & 0 & 0 \\
\hline 20 & 0 & 0 & 0 & 0 & 0 & 0 & 9 & 1 & 0 \\
\hline 30 & 2 & 0 & 0 & 1 & 0 & 0 & 4 & 1 & 0 \\
\hline 40 & 15 & 0 & 0 & 10 & 0 & 0 & 3 & 18 & 0 \\
\hline 50 & 1 & 0 & 0 & 1 & 0 & 0 & 1 & 2 & 1 \\
\hline 60 & 1 & 1 & 0 & 2 & 1 & 0 & 2 & 2 & 1 \\
\hline 70 & 0 & 0 & 0 & 1 & 14 & 1 & 1 & 1 & 15 \\
\hline 80 & 0 & 1 & 0 & 4 & 4 & 0 & 1 & 0 & 4 \\
\hline 90 & 1 & 1 & 0 & 1 & 2 & 2 & 1 & 0 & 1 \\
\hline 100 & 0 & 2 & 1 & 1 & 2 & 1 & 1 & 0 & 1 \\
\hline 110 & 1 & 0 & 1 & 1 & 1 & 0 & 0 & 0 & 2 \\
\hline 120 & 1 & 12 & 0 & 0 & 1 & 10 & 0 & 0 & 0 \\
\hline 130 & 0 & 1 & 1 & 1 & 0 & 3 & 2 & 0 & 0 \\
\hline 140 & 0 & 1 & 10 & 1 & 0 & 3 & 0 & 0 & 0 \\
\hline 150 & 0 & 0 & 2 & 0 & 0 & 0 & 0 & 0 & 0 \\
\hline 160 & 0 & 0 & 0 & 0 & 0 & 1 & 0 & 0 & 0 \\
\hline 170 & 0 & 2 & 1 & 0 & 0 & 0 & 0 & 0 & 0 \\
\hline 180 & 1 & 0 & 1 & 0 & 0 & 1 & 0 & 0 & 0 \\
\hline 190 & 0 & 0 & 0 & 0 & 0 & 1 & 0 & 0 & 0 \\
\hline 200 & 0 & 0 & 1 & 0 & 0 & 0 & 0 & 0 & 0 \\
\hline 210 & 1 & 0 & 0 & 0 & 0 & 2 & 0 & 0 & 0 \\
\hline 220 & 0 & 0 & 0 & 0 & 0 & 0 & 0 & 0 & 0 \\
\hline 230 & 0 & 0 & 0 & 0 & 0 & 0 & 0 & 0 & 0 \\
\hline 240 & 0 & 0 & 1 & 0 & 0 & 0 & 0 & 0 & 0 \\
\hline 250 & 0 & 2 & 1 & 0 & 0 & 0 & 0 & 0 & 0 \\
\hline 260 & 0 & 0 & 0 & 1 & 0 & 0 & 0 & 0 & 0 \\
\hline 270 & 0 & 0 & 1 & 0 & 0 & 0 & 0 & 0 & 0 \\
\hline 280 & 0 & 1 & 1 & 0 & 0 & 0 & 0 & 0 & 0 \\
\hline 290 & 0 & 0 & 1 & 0 & 0 & 0 & 0 & 0 & 0 \\
\hline 300 & 1 & 1 & 2 & 0 & 0 & 0 & 0 & 0 & 0 \\
\hline $\begin{array}{c}\text { Number } \\
\text { of } \\
\text { measure } \\
\text { ments }\end{array}$ & 25 & 25 & 25 & 25 & 25 & 25 & 25 & 25 & 25 \\
\hline
\end{tabular}

This table shows how much time is spent by the thermometers to measure $35^{\circ} \mathrm{C}$ for a fingertip, $36.6^{\circ} \mathrm{C}$ for an armpit and $36.9^{\circ} \mathrm{C}$ for an ear canal.

Based on the results of the experiments, it can be concluded that the Dallas 18B20 thermometer can be used as a temperature sensor for a clinical thermometers.
In addition, as mentioned above, thanks to the one-wire protocol (it provides to wire up to 127 Dallas 18B20 sensors at the same time), this sensor allows us to measure temperature simultaneously in hundreds of places of the human body which makes it possible to build a picture of blood circulation by a comparative analysis of temperatures. For example, it may be enough to use 10 sensors on each arm and leg to determine a place where poor blood movement is. 
Unfortunately, this method cannot study the state of blood circulation in the head and internal organs.

\section{AN AUTOMATED SYSTEM FOR PROCESSING THE RESULTS OF CONTINUOUS TEMPERATURE MEASUREMENT OF VARIOUS PARTS OF THE BODY.}

As it is known, human body temperature can be measured invasively and not invasively. Since our article is devoted to monitoring the body temperature of newborns, young children, chronic patients and the elderly bedridden, and also, electronic devices are used in measuring temperature, we restrict ourselves to measuring temperature in various parts of the skin.

In order to observe the state of blood circulation, we choose three points of the body as measurement points: the armpit, where the average temperature should be from 36 to $36.9^{\circ} \mathrm{C}$, the tips of the fingers and toes, where temperatures can be from 28 to $36.6^{\circ} \mathrm{C}$ and from $24^{\circ} \mathrm{C}$ to $36.6^{\circ} \mathrm{C}$, respectively (although the sources indicate [20] that their average temperatures are $28.5^{\circ} \mathrm{C}$ and $24.4^{\circ} \mathrm{C}$, respectively, authors' finger and toe temperatures were $35.5^{\circ} \mathrm{C}$ as a result of 2 minutes measuring - an author).

Figure 6 shows the average temperature of the parts of the body skin of a healthy person.

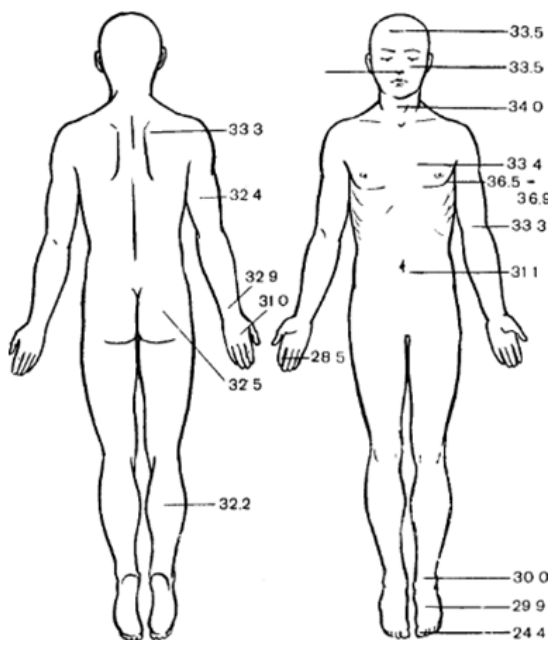

Fig. 6. The average temperature of the parts of the body of a healthy person [20].

To automate the processing of measurement results and state of health monitoring, a simple device. It can be used both constantly for newborns, people with disabilities, elderly people and patients who cannot advance on their own, and when necessary, when a person does not feel well and wants to measure his or her temperature. Therefore, it must be safe, compact and convenient for long-term use.
The device is designed to perform the following functions:

- temperature measurement on three parts of the human body (on the armpit, on the tips of the fingers, on the tips of the toes) using miniature temperature sensors;

- processing of received signals using a microcontroller;

- indication of temperatures on the screen of the liquid crystal monitor;

- giving a light signal with the help of diode lamps of different colours;

- sounding at critically high temperatures.

Below basic properties of the technical means necessary to build the proposed device have been presented.

Arduino Nano microcontroller is a compact microcontroller with a size of $1.85 \mathrm{~cm} \mathrm{x} 4.3 \mathrm{~cm}$, program memory $32 \mathrm{~Kb}, 2 \mathrm{~K}$ RAM, 8 analog inputs, 14 digital inputs / outputs (6 of them with PWM capability), with low power consumption (maximum current of one output is $40 \mathrm{~mA} /$ hour), with a clock frequency of $16 \mathrm{MHz}$.

Miniature temperature sensor DS18B20 (Fig. 13) - Dallas digital temperature sensor. It sends temperature data using only one digital output and a special protocol called 1-Wire.

It is possible to connect multiple sensors to one three-wire cable. The sensor measures the temperature in degrees Celsius. Temperature conversion time at maximum resolution (12 bits) is $750 \mathrm{~ms}$, energy consumption is $4 \mathrm{~mA} / \mathrm{h}$, sensor dimensions are $4.5 \mathrm{~mm} \times 4.5 \mathrm{~mm} \times 4 \mathrm{~mm}$ without legs, waterproof TO-2 housing, has a unique MAC address

The LED 1602 liquid crystal display with the I2C set-top box (Figure 7) - a monochrome text display with the ability to illuminate the screen. The number of characters is $32(16 \times 2)$. The $\mathrm{I} 2 \mathrm{C}$ set-top box allows to control all 32 characters using only 4 wires (VCC, GND, and 2 signal wires). Display dimensions are $7 \mathrm{~cm} \times 2 \mathrm{~cm}$.

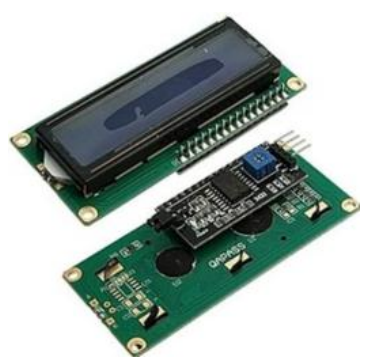

Fig. 7. LED 1602 liquid crystal display with the I2C set-top box (source:www.aliexpress.com)

Also, it is used LEDs of red, white, green and blue colours, a passive buzzer for sounding, a resistor with a resistance of $4.7 \mathrm{kOhm}$, a rechargeable battery with a voltage of 7 volts for autonomous power supply of the device. 
The above details may be assembled in one box. The arrangement and connection of device parts is shown in Figure 8.

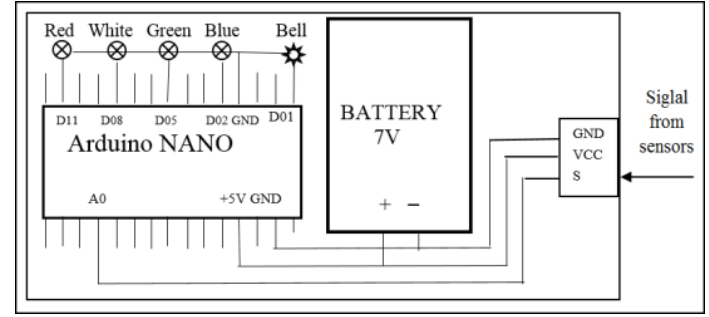

Fig. 8. Layout and connection details.

GND is the zero terminal of the microcontroller (it is usually called grounding), VCC is the positive terminal of the microcontroller with a DC voltage of +5 volts, $S$ is the input signal coming into the device from thermal sensors, A0 is the analog pin (terminal) of the microcontroller receiving the signal from the sensors, D01, D02, D05, D08, D11 - digital outputs of the microcontroller, Red, White, Green, Blue - diode lamps of red, white, green and blue, respectively, Bell - a sound device, Battery - a rechargeable power source of +7 volts DC.

In order to attach temperature sensors to the human body, they are simultaneously soldered to one cable (see Fig. 9). Sensors may be attached to the skin by medical adhesive plaster which helps sensors to measure real temperature keeping heat from spreading out. Also, may be used some skin belts like wrist watch`s one as well as pulse sensor finger clip.

When the sensors are attached to the human body, they simultaneously begin to send a signal through one cable. The controller can recognize their signals by their unique addresses, reminiscent of the MAC addresses of devices.

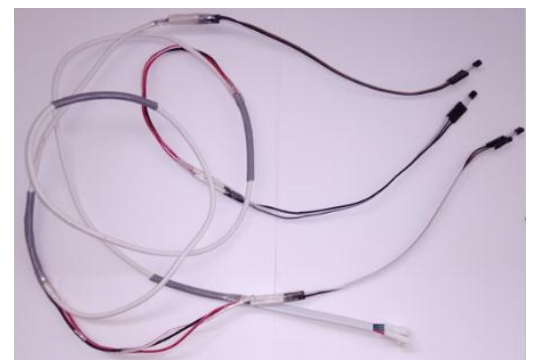

Fig. 9. Temperature sensors soldered to one cable.

The signal from the remote temperature sensors is delivered through a cable (see Figure 9) to the terminal indicated by the letter $\mathrm{S}$ in the diagram (see Figure 8). The terminal is connected to pin A0 of the microcontroller. After processing the signals, the microcontroller sends the necessary control signals to the LEDs Red, White, Green, Blue and the buzzer Bell through the digital pins D11, D08, D05, D02, D01, respectively.

\section{A SIGNAL PROCESSING ALGORITHM}

To process the signals, the limits of normal temperatures for various parts of the body must be set. They are described in details in the article [21].

Let qoltiq_t, qol_t, oyoq_ $t$ denote the real temperatures at the armpit cavity, at the tips of the fingers and toes, respectively, qoltiq_low and qoltiq_high - the lower and upper boundaries of the normal temperature of the armpit, and qol_low and oyoq_low - the lower boundaries of the normal temperature of the fingers and toes respectively. Then the following inequalities are true:

$$
\begin{aligned}
& \text { qoltiq_low }=36 \leq \text { qoltiq_t } \leq 36,9=\text { qoltiq_high, } \\
& \text { qol_low }=\overline{2} 8 \leq q o l \_t \text {, } \\
& \text { oyoq_low }=24 \leq \text { oyoq_t } \text {. }
\end{aligned}
$$

According to the results of measuring real temperatures, the following special cases can be distinguished.

Case 1: all temperatures are within normal limits - the controller turns on a green LED.

Case 2: the temperature of the armpit cavity is below normal to $2{ }^{\circ} \mathrm{C}$ - moderate hypothermia - the controller turns on the blue LED.

Case 3: the temperature of the armpit cavity below the norm is more than $2{ }^{\circ} \mathrm{C}$ - dangerous hypothermia - the controller sends a flashing blue LED.

Case 4: the temperature of the armpit cavity is from 37 to $38{ }^{\circ} \mathrm{C}$, the difference between the temperatures of the fingers and toes does not exceed $8{ }^{\circ} \mathrm{C}$ and $12{ }^{\circ} \mathrm{C}$, respectively - moderately high temperature - the controller turns on a white LED.

Case 5: the temperature of the armpit cavity is from 37 to $38{ }^{\circ} \mathrm{C}$, the differences between the temperatures of the fingers and toes are more than 8 ${ }^{\circ} \mathrm{C}$ and $12{ }^{\circ} \mathrm{C}$, respectively - a moderately high temperature with difficulty in blood circulation the controller turns on both white and blue LEDs.

Case 6: the temperature of the armpit cavity is from 38 to $39^{\circ} \mathrm{C}$, the difference between the temperatures of the fingers and toes does not exceed $8{ }^{\circ} \mathrm{C}$ and $12{ }^{\circ} \mathrm{C}$, respectively - high temperature - the controller turns on the red LED.

Case 7: the temperature of the armpit cavity is from 38 to $39{ }^{\circ} \mathrm{C}$, the differences between the temperatures of the fingers and toes are more than 8 ${ }^{\circ} \mathrm{C}$ and $12{ }^{\circ} \mathrm{C}$, respectively - high temperature with difficulty in blood circulation - the controller turns on both red and blue LEDs.

Case 8: the armpit cavity temperature is from 39 to $41{ }^{\circ} \mathrm{C}$, the difference between the temperatures of the fingers and toes does not exceed $8{ }^{\circ} \mathrm{C}$ and 12 ${ }^{\circ} \mathrm{C}$, respectively - dangerously high temperature the controller flashes a red LED and turns on the blue LED.

Case 9: the temperature of the armpit cavity from 39 to $41{ }^{\circ} \mathrm{C}$, the difference between the temperatures of the fingers and toes is more than 8 ${ }^{\circ} \mathrm{C}$ and $12{ }^{\circ} \mathrm{C}$, respectively - pre-convulsive 


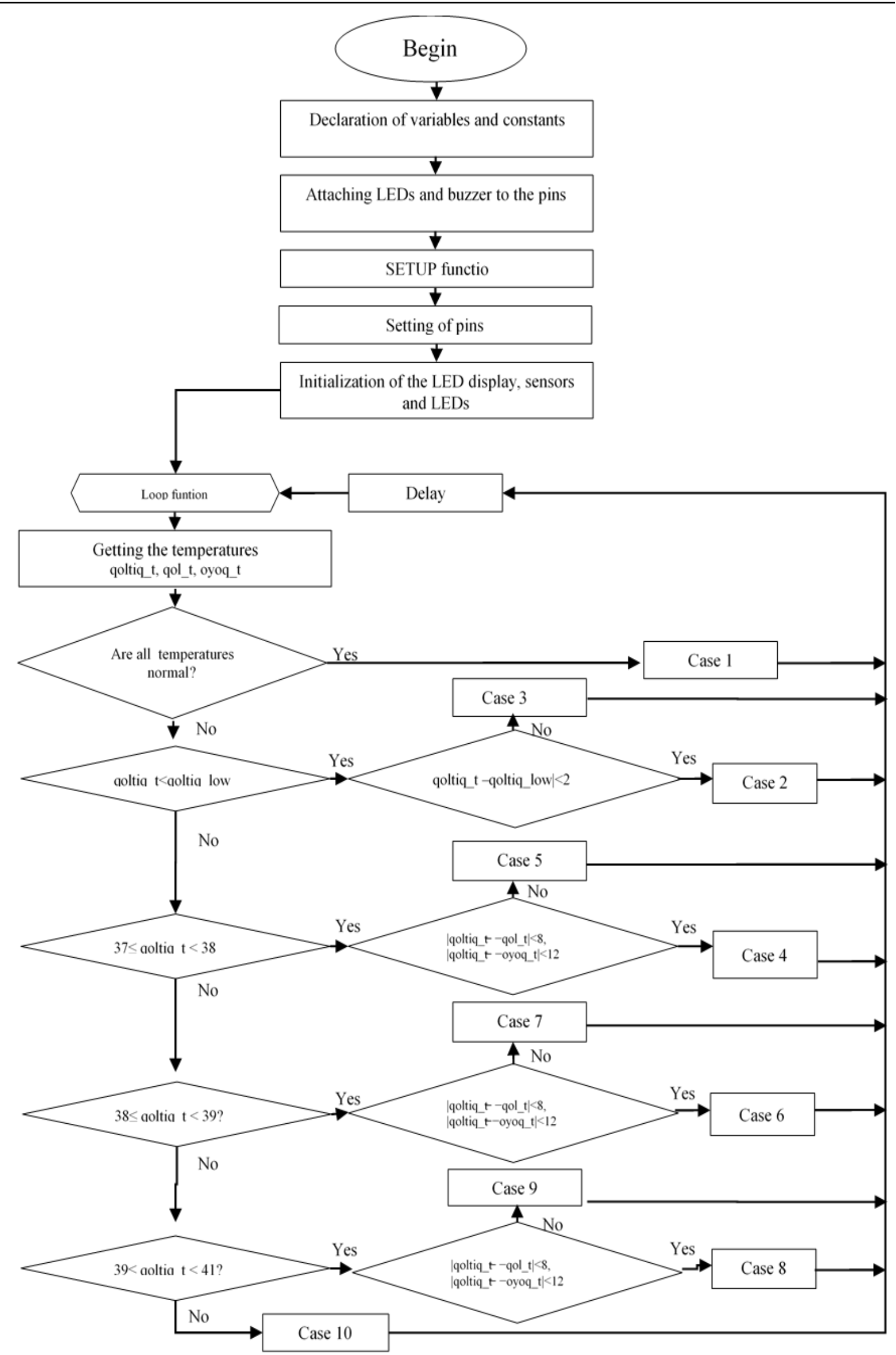

Fig. 10. The block diagram of automated control algorithm of the device. 
condition - the controller flashes red and blue LEDs at the same time, turns on an intermittent sound signal with a frequency of $1 \mathrm{~Hz}$.

Case 10: the temperature of the armpit cavity above $41{ }^{\circ} \mathrm{C}$ - critical condition - the controller flashes red and blue LEDs at the same time, turns on an intermittent sound signal with a frequency of $4 \mathrm{~Hz}$.

The block diagram of this algorithm is shown in Figure 10.

\section{CONCLUSION}

The proposed program performs a comparative analysis of temperature data at various points of the human body and, according to its results, provides information in three directions: about body temperature at several points, about the condition of the limbs of the arms and legs, as well as about the possible causes of this condition.

The code of this program is open in the sense that it can be easily developed by increasing the number of measured temperature points and adding new diagnostic data. And also, its improvement by adding additional conditions for the analysis of temperature data does not require fundamental changes in the structure of the program.

Unlike traditional methods of measuring body temperature at one specific point or at several points in series, this paper proposes the simultaneous measurement of temperature at three points in parallel for comparative analysis.

Based on this program, it is created an initial working model of the device with an automated control system designed to monitor the health status of children and adults with disabilities.

Since the device is mainly intended for children, travellers and people living in remote areas, dimensions of the initial version of device without any optimization and design (dimensions of the layout $-150 \times 100 \times 30 \mathrm{~mm}$ ) allows to carry it in handbags, school bags and, even, if necessary, in pockets (see Figure 11).

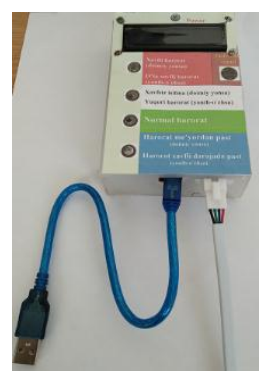

Fig. 11. Automated body temperature signal processing device.

In the future, there is the possibility of a significant reduction in its size.

Also, the control program is open for future developments. There are a lot of possibilities to change parameters such as limits and differences between temperatures, measurement frequency, types of conditional warning signals, etc. Additional buttons can be installed to restart the program, to change the parameters by the users. Storage of the measurement results in the internal memory of the microcontroller and their reading can be organized.

\section{ACKNOWLEDGMENTS}

This work was supported by the Namangan Institute of Engineering \& Technology.

\section{REFERENCES}

1. Romanovsky AA. Thermoregulation: some concepts have changed. Functional architecture of the thermoregulatory system. American Journal of Physiology. Regulatory, Integrative and Comparative Physiology. 2007; 292(1):37-46.

2. Dzerzhinsky F, Vasiliev B, Malakhov V. Zoology of vertebrates. Publication centre "Academy", Moscow, 2014.

3. Rachel $\mathrm{N}$. What is a normal temperature range. https://www.medicalnewstoday.com/articles/323819

4. High temperature in children: friend or foe. AiF. Health, No. 47 11/18/2010.

5. Mendelssohn R. How to Raise a Healthy Child in Spite of Your Doctor: One of America's Leading Pediatricians Puts Parents Back in Control of Their Children's Health. Mass Market Paperback, May 12, 1987.

6. David J, Earn D, Paul W. Andrews, Benjamin Bolker N. Population-level effects of suppressing fever. The ROYAL SOCIETY. Biological Sciences, March 7, 2014.

7. Davis Ch. Fever in adults. https://www.emedicinehealth.com/fever in adults/art icle_em.htm

8. Vasilenko VV. Body temperature measurement. Russian medical journal. 2008;29:1948.

9. Pavlović M, Radlović N, Leković Z, Berenji K. Comparison of different methods of temperature measurement in children. Medicinski pregled. 2008;61(11-12): 615-619.

10. Niven D, Gaudet E, Laupland K, Mrklas K, Roberts D, Stelfox H. Accuracy of peripheral thermometers for estimating temperature: A systematic review and meta-analysis. Annals of Internal Medicine. 2015;163(10):768-777. https://doi.org/10.7326/M15$\underline{1150}$

11. Hang N, Thao P, Dang T, Dinh A. Noncontact Body Temperature Measurement, International Conference on the Development of Biomedical Engineering in Vietnam, BME 2018, Ho Chi Minh, Viet Nam, June 27, 2018.

12. Chen W. Thermometry and interpretation of Biomedical body temperature. Engineering Letters. 2019;9(1):3-17. https://doi.org/10.1007/s13534-019$\underline{00102-2}$

13. Husain M, Naqvi S, Atalay O, Hamdani S, Kennon R. Measuring human body temperature through temperature sensing fabric. AATCC Journal of Research. 2016;3(4):1-12. https://doi.org/10.14504/ajr.3.4.1 
14. Togawa T. Body temperature measurement. Clinical Physics and Physiological Measurement. 1985;6(2): 83-108.

15. Seo Y, DiLeo T, Powell J, Kim J, Roberge R, Coca A. Comparison of estimated core body temperature measured with the BioHarness and rectal temperature under several heat stress conditions. Journal of Occupational and Environmental Hygiene. 2016; 13(8):612-620.

https://doi.org/10.1080/15459624.2016.1161199

16. MacRae B, Annaheim S, Spengler C, Rossi R. Skin temperature measurement using contact thermometry: a systematic review of setup variables and their effects on measured values. Front Physiol. 2018. https://doi.org/10.3389/fphys.2018.00029

17. https://en.wikipedia.org/wiki/Liquid_crystal the rmometer

18. https://www.engineeringforchange.org/solutions /product/thermospot/

19. Salomi Thomas S, Saraswat A, Shashwat A, Bharti V. Sensing heart beat and body temperature digitally using Arduino, Signal Processing, Communication, Power and Embedded System (SCOPES), IEEE International Conference, 2016.

20. Achkasov EE, Volovik MG, Dolgov IM, Kolesov SN. Medical thermal imaging. INFRA-M, Moscow, 2019.

21. Bogdanova TM, Bacutin VV, Bolshakov AA, Bacutin IV, Melnikov LA, Spirin BF. Nalivaeva AV. Human body temperature monitoring and its application in clinical practice. International Journal of experimental education. 2013; 10(2):242-245.

Received 2020-07-14

Accepted 2020-07-13

Available online 2020-07-14
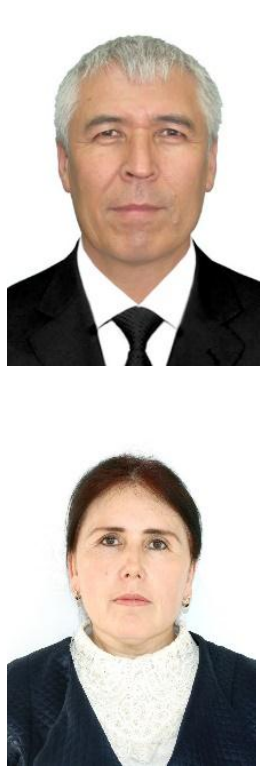

Azambek TURAKULOV, Ph.D, graduated from the National University of Uzbekistan, Novosibirsk State University of Russia. His main interests are making software for solving scientific problems, automated systems, computational mathematics and medical informatics.

Fotima MULLAJONOVA, M.Sc., graduated from Namangan Institute of Engineering and Pedagogy. Her main interests are making software for automated technological systems, signal processing and medical informatics. 